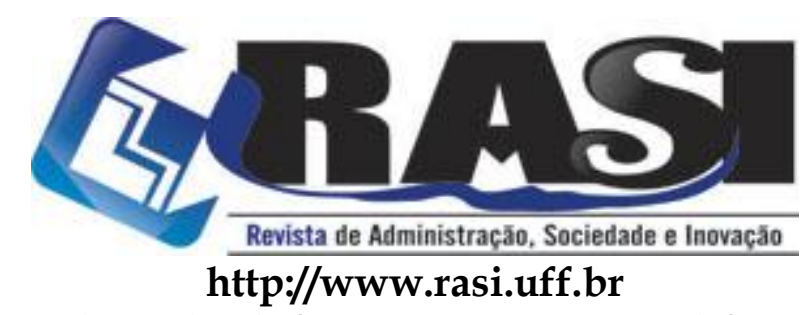

RASI, Volta Redonda/RJ, v. 1, n. 1, pp. 1-3, Jul./ Dez. 2015.

EDITORIAL: Construção de Conhecimentos - uma proposta pluriversal

Márcio Moutinho Abdalla

Universidade Federal Fluminense - UFF

marcioabdalla@id.uff.br

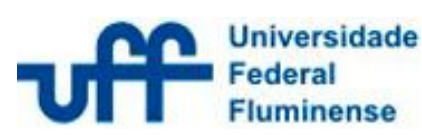

R. Desembargador Ellis Hermydio Figueira, 783, Bloco A, sl. 218, Aterrado.

27213-415 - Volta Redonda, RJ - Brasil

www.uff.br

Copyright ( 92015 RASI. Todos os direitos, até mesmo de tradução, são reservados. É permitido citar parte de artigos sem autorização prévia, desde que seja identificada a fonte. 


\section{EDITORIAL: Construção de Conhecimentos - uma proposta pluriversal}

É com muita satisfação que entregamos à comunidade acadêmica, de praticantes e à sociedade como um todo, o primeiro número da Revista de Administração Sociedade e Inovação (RASI).

A ideia de conceber um periódico que discutisse aspectos da ciência da administração, sem perder de vista os anseios da sociedade e as dimensões da inovação, nasceu em 2011, como uma derivação (ou se preferirem, spin-off) do Congresso de Administração, Sociedade e Inovação, realizado anualmente pelo Departamento de Administração de Volta Redonda-RJ, da Universidade Federal Fluminense (UFF).

A proposta ganhou mais vigor a partir da consolidação do Programa de Pós Graduação em Administração, por meio do Mestrado Profissional em Administração, a partir do aludido departamento. Rotineiramente éramos pegos falando da necessidade de conceber um "produto" que materializasse nossa identidade acadêmica e institucional.

Contudo, a editoria de um periódico deve se revestir de responsabilidades maiores que apenas discutir aspectos dos campos de conhecimento. $\mathrm{O}$ processo requer atenção e cuidado. Refiro-me não apenas às muitas regras e procedimentos que blindam a ideia de rigor científico e metodológico, mas especialmente responsabilidade, atenção e cuidado frente à inovação e à diversidade em pesquisas organizacionais (Alvesson \& Gabriel, 2013). Não é raro nos depararmos com colegas "torcendo o nariz" para pesquisas e estudos que fogem aos tradicionais moldes que estamos habituados. Felizmente, aos poucos, temos visto ações (e atores) caminhando na direção da diversidade e da pluriversalidade, sobretudo de forma respeitosa. Afinal de contas, discordar não é guerrear! É preciso nos apoderarmos da essência do verbo discutir, e não tratá-lo como sinônimo de confronto, mas sim de debate e argumentação.

Em meio a uma era de intolerância, avançamos com uma proposta que preconiza a coexistência e a multiplicidade de conhecimentos, tal qual vem defendendo o filósofo argentino Enrique Dussel (Dussel, 2005; 2011; 2013), sem que, no entanto, percamos o rigor científico e metodológico. Nesse primeiro número, caminhamos com a proposta de uma linha editorial que prestigie a ideia cosmopolita, de sempre agregar novas discussões e novas geografias do conhecimento.

A partir dessa lógica, abrimos a edição com o trabalho "Busca de informações no processo de locação de imóveis: uma análise com clientes do município do Rio de Janeiro"de Danillo Rodrigues da Cruz, que se propõe a analisar a busca de informações sobre o processo de locação de imóveis a partir da opinião de clientes do Rio de JaneiroRJ.

Ainda no campo da administração, mais especificamente em marketing, o trabalho "Clínica Olhar: Análise da Satisfação dos Clientes em Relação ao Serviço Prestado", de Joyce Gonçalves Altaf, Danilo M. Matos, Letícia Tasca Tavares, Oswaldo Alves dos Santos Júnior e Regilene Imaculada N. Lima objetiva medir a satisfação em serviços a partir de uma investigação com clientes da clínica oftalmológica Olhar. 
O terceiro trabalho, "Gerenciamento de Procedimentos Operacionais através de Sistema Informativo: Estudo de Caso da KB Cervejarias", de Luan Eloy de Lima e Flávia Roberta Ferreira de Souza, analisa o gerenciamento de procedimentos operacionais na empresa KB Cervejarias, que atua no mercado cervejeiro de ManausAM.

Das empresas para a sociedade, o quarto trabalho, "Investimentos em Ações de Responsabilidade Social no Brasil: uma Análise Quantitativa", de Eduardo Aguiar Silva, Denise Carneiro dos Reis Bernardo, Fabrício Molica Mendonça e João Paulo de Brito Nascimento, questiona se os investimentos em ações de Responsabilidade Social Corporativa variam segundo o setor econômico das empresas que os realizam.

Fechamos a primeira edição com um trabalho que se situa no campo de públicas, especificamente voltado à análise de políticas públicas de saúde frente ao enfrentamento e combate ao mosquito da dengue no município de Comendador Levy Gasparian-RJ. Intitulado "O trabalho Investigação da política municipal de Comendador Levy Gasparian de combate à dengue", o trabalho tem autoria de Patricia Fernanda dos Santos de Loureiro Nunes e Yuna Souza dos Reis da Fontoura.

Em nome da equipe editorial, desejo a todos uma excelente leitura!

Márcio M. Abdalla

Editor Chefe

\section{Referências}

Alvesson, M., \& Gabriel, Y. (2013). Beyond formulaic research: In praise of greater diversity in organizational research and publications. Academy of Management Learning \& Education, v.12, n.2, pp.245-263.

Dussel, E. (2005). Filosofia da Libertação: Crítica à Ideologia da Exclusão. $3^{\mathrm{a}}$ Ed. São Paulo: Paulos.

Dussel, E. (2011). Transmodernidad e interculturalidad (interpretacion desde la filosofia de la liberacion). In.: Lander, E. (Org.). La colonialidad del saber: eurocentrismo y ciências sociales (2a ed.). Buenos Aires: Clacso.

Dussel, E. (2013). Ethics of liberation: In the age of globalization and exclusion. Duke University Press. 